\title{
Non-verbal Communication Used by Parents to Their Children in Presence of Visitors in Ovoko
}

\author{
Bestman Esegbuyiota Odeh \\ Department of Linguistics, Igbo \& Other Nigerian Languages, University of Nigeria, Nsukka, Nigeria \\ Linda, Abugu \\ Department of Linguistics, Igbo \& Other Nigerian Languages, University of Nigeria, Nsukka, Nigeria \\ Jacinta Ukamaka Eze \\ Department of Linguistics, Igbo \& Other Nigerian Languages, University of Nigeria, Nsukka, Nigeria \\ Juliana Ginika Mamah \\ Department of Linguistics, Igbo \& Other Nigerian Languages, University of Nigeria, Nsukka, Nigeria \\ Augustina Ngozi Eze \\ Department of Linguistics, Igbo \& Other Nigerian Languages, University of Nigeria, Nsukka, Nigeria
}

\begin{abstract}
This study examines the use of non-verbal communication by parents to their children in presence of visitors in Ovoko speech community, Enugu state, Nigeria. The specific objectives of the study are: to identify various body communication signs used by parents to their children in presence of visitors and to provide the interpretations in the speech community under study. Primary methods of data collection are adopted which is observation and interview. From the pictures gathered from the field, a total of ten (10) facial and body expressions are selected for analysis in this study. The study adopts the social semiotic theory as a theoretical framework for its analysis. The study identifies various body signs used by parents to their children. It further reveals that all expressions used by the population have meanings attached to them. The study therefore, recommends that a study of the children's interpretation and opinion of the parents' body expression is a worthwhile academic undertaking in other to ascertain if the right perlocutionary response to the sign is always achieved.
\end{abstract}

Index Terms - communication, non-verbal expression, Ovoko, semiotics

\section{INTRODUCTION}

Language, a major trait that distinguishes homo-sapiens from other beings, is a vehicle through which realities are conceived, perceived and expressed. It is acquired through a process of socialisation in the culture of the group that uses it. Language is only a means of communicating information; it is an essential means of establishing and maintaining relationship with other people. It gives listeners clue about speakers' origins and the sort of people they are. It is a tool used for expression of one's mind. Fridlund (1994) avers that expressions evolved to elicit behaviours from others. Some expressions can be accurately interpreted even between members of different speech communities -anger and extreme contentment being primary examples. Others are problematic to interpret even among a particular group of individuals. One can say that the main purpose of the use of language is for communication. According to Bloch and Trager (1942), language is a system of arbitrary vocal symbols by means of which cooperation among social groups is made possible. It is the basic instrument for social behaviour. Communication is the conveyance of feelings, thought, ideas, intentions, and the likes to one another, and for humans, it is peculiarly done verbally.

The importance of communication cannot be over emphasised. Communication serves all humans as a culturally inherited and institutionalised implement created through time by any given speech community. It helps members of family to use their faculty of speech to meet their communicative needs through family interaction. Therefore, irrespective of the social group or class anyone belongs to, the essence of language is to communicate.

People communicate with each other in a number of ways depending on the message and its context. Invariably, these different styles of expression exert effects on communication. Communication can be in form of verbal or nonverbal. These types of communication are used based on the communication channels adopted. Verbal communication refers to the form of communication in which message is transmitted verbally and communication is done orally or in written form. The objective of communication is to have people understand the message we want to convey. Verbal communication uses spoken words to communicate a message. Most people think of verbal communication as just speaking, but in addition to that, listening is equally an important skill for this type of communication to be successful. 
Verbal communication is applicable to a wide range of situations, ranging from informal, office discussions to public speeches made to tens, hundreds or even thousands of people.

Non- verbal communication is the sending or receiving of messages without vocal sound. It can be said to be that information passed across through means such as posture, gesture, body language, tone of voice or facial expressions. It is all about the body language of the encoder. Non-verbal communication may convey any aspect of communication that is not purely verbal. More precisely, non-verbal communication can be viewed from two angles. From one angle, non-verbal communication refers to people's actions or attributes other than words (Verderber, 1975). Coming from this perspective, Burgoon and Saine (1978) define non-verbal communication as all those attributes or actions which humans exhibit or receive intentionally or consciously, that have socially shared meaning instead of using speech, and have the unrealised ability to elicit feedback from the receiver. From another perspective however, non-verbal communication also refers to elements that are not from, neither are they part of, people but that communicate through people's use of them. Thus, such artefacts and environmental factors as clothes, temperature and colour fall within the realm of non-verbal communication. Mikoluk (2013) argues that non-verbal communication sets the tone of a conversation, and can seriously undermine the message contained in the speaker's words if it not carefully controlled.

Cherry (2018) listed some forms of non-verbal communication among which facial expression is considered responsible for a huge proportion of it, considering how much information can be conveyed with a smile or a frown. The look on a person's face is often the first thing one sees, even before they hear what the person has to say. For example, we can combine a frown with crossed arms and unblinking eye gaze to convey disapproval. Non-verbal communication and behaviour can vary dramatically between cultures; however, facial expressions for happiness, sadness, anger, and fear are similar throughout the world. Moreover, body language, posture and movement can also convey a great deal of information. Common gestures include waving, pointing, and using fingers to indicate numeric amounts.

The interpretations of the different non-verbal communication signs pose a challenge to those who are not conversant with them. Also, the use of some of these expressions may be very misleading as they can be ambiguous. This is because different contexts of use can bring about different interpretations. There is the need to study non-verbal signs especially the ones that exist between parents and children when visitors are around at home and what they imply. This work therefore is to identify various non-verbal signs used by parents to their children in presence of visitors at home and to provide the interpretations as used in the speech community where we are studying.

This study is carried out in Ovoko speech community in Enugu state, Nigeria. Also, the study is an observational study and the data that are used in this research work are collected based on participant-observation and interview. This method is chosen so as to gather relevant information which could not be easily obtained if the researchers observe in a disinterested fashion. A phone camera is used to capture the expressions of a selected few during the observation.

\section{LITERATURE REVIEW}

Carter (2000) explores the use of front-page photographs in newspapers and the interpretation of the images by readers using semiotic analysis. The study argues that there are many decisions taken by the photographer such as focusing, lighting and the angle that produces various representations and readings and at the same time create different connotations. From the choices made from the paradigm sets of these signifiers and the syntagmatic relationship between them, it is possible to decode and compare the front page photographs from newspapers. In the study, Carter concludes that although a semiotic analysis can determine the meanings embedded in a photograph, it cannot determine the reader's interpretation of the text in a social context. It can only serve as an insight to the conventions that different newspapers employ and the responses that are attached to the codes at work within them. The two research works are carried out on non-verbal communication though with different objectives.

Tsotra, Janson and Cecez-Kecmanovic (2004) carry out a semiotic analysis of marketing on the internet. The objectives of their study are to examine two examples of internet marketing and explore the manner in which potential customers from different cultural backgrounds perceive advertised products. The researchers employ semiotic theory as a framework of analysis in the study. The study reveals that customers from different cultural backgrounds create meaning in different ways. It also unveils the fact that alternative visual categories are relevant to different groups of people. In as much as these two research works are anchored on semiotic analysis, they have objectives different from each other.

In another study, Ferreira, Barr \& Noble (2005) conduct a literature review on the role and place of semiotics in the design of user interface in a computer system. This is born out of the realisation that the proportion of non-technical users has grown over the years. Consequently, the interaction style and interpretability of the user interface determines its success. The review found out that computer interface redesigns are implemented once they are tested on users and subjected to an expert evaluation. Hence, semiotics can help the designers to better the communication power of the user interface. The designer combines various signs to make up the interface in order to convey its intended meaning. This from their own view is achieved through buttons, scroll-bars and significant images, all contributing to the power of communication. From the literature review of user interfaces, it emerged that semiotic analysis is a strong tool for use in analysing the communicability and interpretability of user interfaces in computers by applying the Peircian model of the sign. The designs of user interfaces are inclined to be in the form of iconic, indexical and symbolic signs. This 
should make designer aware of the benefits of iconic, symbolic and indexical representation of functionality of user interfaces. Although, the two studies are related as they study the use of signs, one of their differences is the fact that while Ferreira, Barr \& Noble (2005) based the objectives of their study on the role and place of semiotics in the design of user interface in a computer system, this present study is based on the use of non-verbal communication by parents to their children in presence of visitors at home.

Remland (2008) studies non-verbal communication in everyday life in West Chester University of Pennsylvania with the following objectives: to present the following codes: primary functions and development of non-verbal communication; to take on integrative approach and show how each channel serves a primary function and to offer a sound application of non-verbal communication grounded in the best and latest theory and research to help students achieve success in various, common and everyday situation. His work on non-verbal communication in everyday life employs a highly qualitative approach in the analysis of data sourced from interviews, participant observation and Focal Group Discussion (FGD), however, secondary data source is employed to this effect. The study finds out that nonverbal communication is an everyday life affair and as such, students make use of it in their daily interaction both consciously and unconsciously. This study is similar to the present work as it focuses on the use of many different parts of the body for non-verbal communication as the present work does. However, while this work is anchored on the use of body language among the students, the present work is anchored on the use of non-verbal language by parents to their children.

Eberhardinger (2012) carries out a synchronic textual analysis on Japanese manner posters from the 1970s to 1980s. The study aims at unpacking a cultural code commissioned by Hideya Kawakita, a Japanese artist. The study shows that Japanese manner posters act as communicative medium for commuters to follow rhetorical directives in public transportation sites. It is also found that crowded Japanese context rely mostly on non-verbal communication such as poster for civil cooperation. The study is of the opinion that icons serve as metaphors for people in their everyday societal life. This analyses Japanese manner posters while the current study investigates the use of non-verbal language by parents to their children. Nevertheless, the two studies are based on the use of sign languages.

Feng and O'Halloran (2012) investigate the way emotive meaning is represented in visual images using the semiotic resources of facial expression, touch and body positioning. Using social semiotic framework, the study draws up facial expression, touch and body alignments as inter related systems of meaning of which the selection and combination constitute a systemic functional "lexico grammar" for analysing and interpreting meaning creation in visual imagery. The systems are employed in explaining the way emotive meanings are represented in iconic books. Finding shows that cartoonists' systemic choices for representing emotions are mostly consistent with the coding accuracy of facial expression on one hand and style guideline on the other hand. The study also shows that the social semiotic framework is effective in explaining the emotion resources in non-verbal behaviour and also useful in investigating cultural differences in the visual depiction of emotion. Although, the two research papers aim at explaining the emotive meanings represented in pictures, they are different in that as Feng and O'Halloran analyse pictures in a comic book, the current study is based on non-verbal communicative expressions of parents in Ovoko speech community to their children in presence of visitors.

Okoro and Day (2013) study non-verbal behaviour in intercultural communication between Nigerians and nonNigerians during business transactions. Their objective is to investigate the extent to which Nigerian business people adapt to their non-verbal communication style when conducting business with non-Nigerians as well as with other Nigerians. They employed the use of survey and face-to-face interview method where specific non-verbal communication variables which include silence, non-verbal feedbacks, facial expressions, voice volume, gestures, and eye contact were used. This work identifies unique non-verbal signs essential for effective business communication in Nigeria. The study suggests the importance of identifying adjustment strategy associated with non-verbal behaviour in intercultural business transactions in Nigeria. The two works are related as they study the use of non-verbal communication in Nigeria. Besides, their divergence lies the fact that while the previous study addresses the intercultural communication between Nigerians and non-Nigerians during business transactions, the current study focuses on the use of non-verbal language by parents to their children.

Dzanic (2013) explores the extent to which semiotics aids in explaining how signs were used to represent something. The study seeks to investigate the switching from denotative to connotative meanings of advertisements. The approach is based on the assumption that communication is accomplished through decoding and encoding messages. The connotative meaning represents the overall impression about the meaning of the product which an advertisement creates by the use of the image or icon (e.g. the photographed model). The study then argues that through the use of symbolism and iconicity, a customer is made to believe that a product or service is the ultimate solution to their problems and something that makes their wishes come true. The area of convergence between these two works is in the study of the use of signs to communicate. However, their objectives vary. While the previous work studies the semiotics of contemporary advertising messages from the decoding visual point of view, the present work studies the use of nonverbal language by parents to their children.

The reviews so far, looked at the findings of different authors on studies of body expressions which are very important aspects of non-verbal communication. Most of the works above focused on parts of the body used for 
expressions. This work differs greatly from others because it looks at the interpretation of the body expressions of parents to their children in presence of visitors.

\section{Theoretical Framework}

\section{Semiotic Theory}

Semiotics as a field of study that is concerned with the science of signification is often said to derive from two sources: Charles Sanders Peirce (Anglo-American, 1839-1914) and Ferdinand de Saussure (Swiss-French, 1857-1913). Some other prominent scholars known for their works in semiotics are Eco (1976), Barthes (1967) and Baudrillard (1988). Semiotics is the theory that deals with the production and interpretation of meaning. Its basic principle is that meaning is made by the deployment of acts and objects which function as "signs" in relation to other signs.

In linguistics, how people use signs and body to communicate is studied under semiotics. It is the study of signs in general. Semiosis as a term is the ability of all living things to produce and understand signs involuntarily (Sebeok, 2001). It is the human capacity and process of making and using signs. Semiotics can be traced as far back as $460-377$ B.C. in the study of physiological symptoms of diseases. It developed over time but the first linguists to be associated with the study of semiotics is Ferdinand de Saussure and Charles S. Peirce. Their study of semiotics aims at understanding the structures undergird both the production and interpretation of signs (Sebeok, 2001). The structuralist semiotics is of the opinion that the recurring patterns which are the properties of sign system are reflective of inherent structures in the sensory, emotional and intellectual composition of human body and psyche. de Saussure (1916) proposes two branches of semiotics thus: diachronic and synchronic semiotics. From Saussurean's point of view, sign is a form that is made up of a physical reality (which Saussure himself terms "signifier") and the image or concept which is the referent of that physical reality (Saussure calls it the "signified"). Then the connectivity between the signifier and the signified is what he called signification (Sebeok, 2001). de Saussure contends that there is no natural connection between the signifier and the signified; their connection is arbitrary. In Peirce own words according to Sebeok (2001), signifier is termed "representame" while the signified is called "the object". The proponent also notes that based on the usage and situation, most human signs have the ability to encode two primary kinds of referent - denotative and connotative. Peirce classifies signs into three, thus: icon, index and symbol. Icon resembles or recreates the perceptual experience of the referent; index shows a referent through /causal relationship between the signifier and the signified while symbol represents the referent arbitrarily. In all, there are six types of sign (Sebeok, 2001): symptom, signal, name, icon, index and symbol.

Hodge and Kress (1988) criticise the structuralist semiotics of Ferdinand de Saussure on the basis of its inability to address the issue of how societies and cultures maintain or shift the conventional link between the signifier and the signified. They also complained that Ferdinand de Saussure dodged addressing the issue of creativity, movement and change in language owing to the reaction to the diachronic linguistics of the time.

Social semiotics is a communicative approach which aims at understanding the manners at which people communicate through a variety of modes in a particular social situation. From this angle, the study of communication identifies and invents the semiotic options that are available to the communicators and that which they chose to make. In other words, people choose from semiotic resources at their disposal to express meanings in a given social context and at a given point in time. It is a theory that is based upon meaning and socio-cultural context. Social semiotics explores the manner at which cultural contexts produces representations and how these representations contribute to cultural settings (Jewitt and Henriksen, 2016). Put differently, social semiotics aims at investigating the social functions and meaning possibilities of cultural settings and representations in the communicative terrain.

The term 'social semiotics' emerged in linguistics following the work of Michael Halliday in the Book he entitled 'language and social semantics' (Halliday, 1978). In this work, language is perceived as sets of resources that influence what the speaker can do with language in a particular social situation. On the other hand, the work of Hodge and Kress (1988) which is entitled 'social semiotics' deals basically with the use of semiotic system in social practice; shifting emphasis from language to other modes or rather other resources available for use to produce sign in a communicative enterprise. They toe the perspective of Charles Sanders Peirce by referring to his classifications of sign as icon, index and symbol. Through these classifications, Hodge and Kress are able to address the issue of how the society and culture maintain or shift the conventional link between signifier and the signified.

This study adopts the social semiotic approach of Hodge and Kress (1988) which promotes the choice from the available semiotic resources to express meaning given a particular situation and time without being restricted to only verbal mode.

\section{DATA PRESENTATION AND ANALYSiS}

Here, the pictures of different gestures exhibited by parents in the bid to communicate to their children without attracting the attentions of their visitors are presented and analysed.

\section{A. Identification of Body Expression Used by Parents to Their Children in the Presence of Visitors.}

Different body expressions as identified from the study area will be represented here using figures. 


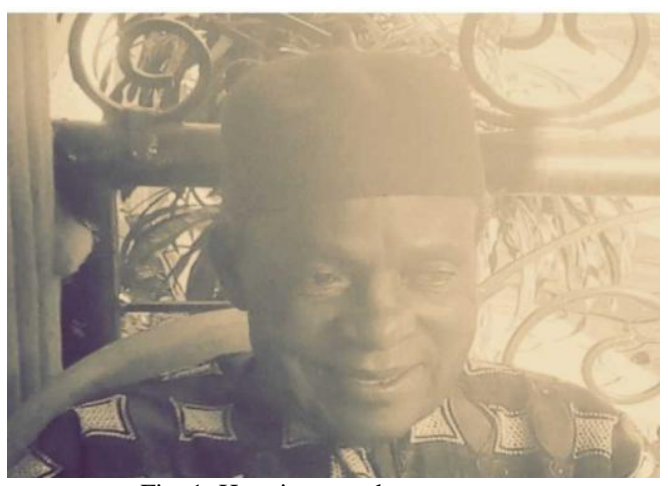

Fig. 1: Happiness and contentment

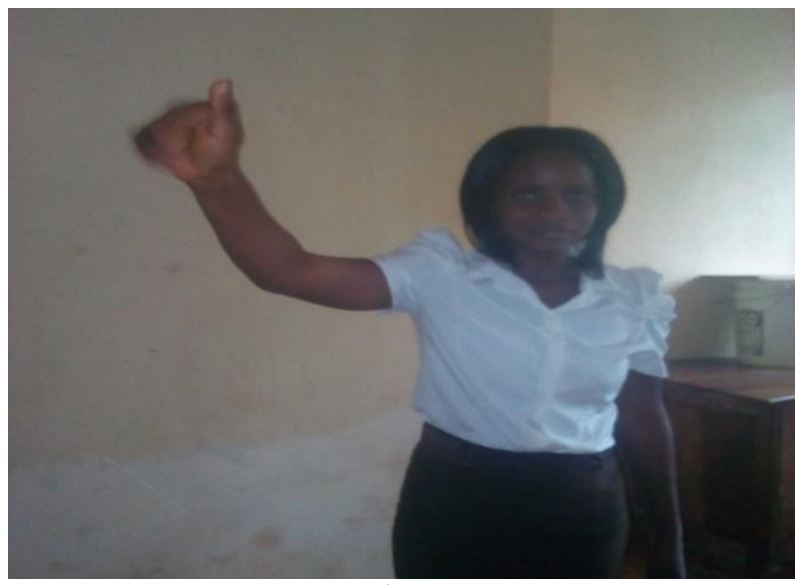

Fig. 2 This denotes "come"

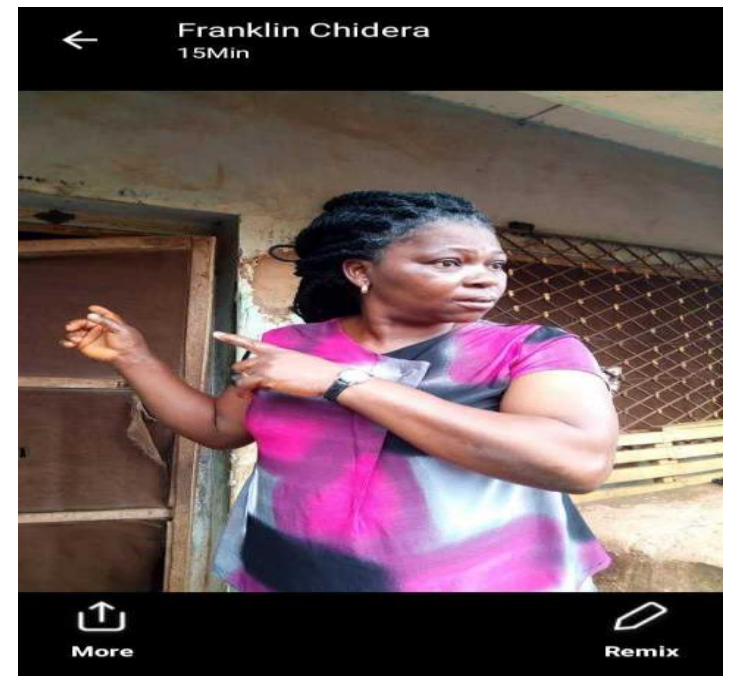

Fig. 3 This denotes anger and the injunction to go in

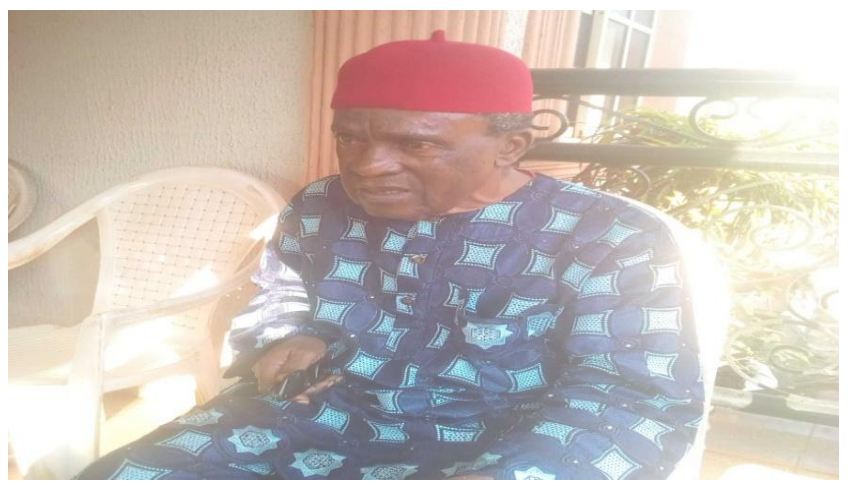

Fig. 4: This denotes surprise and shock. 


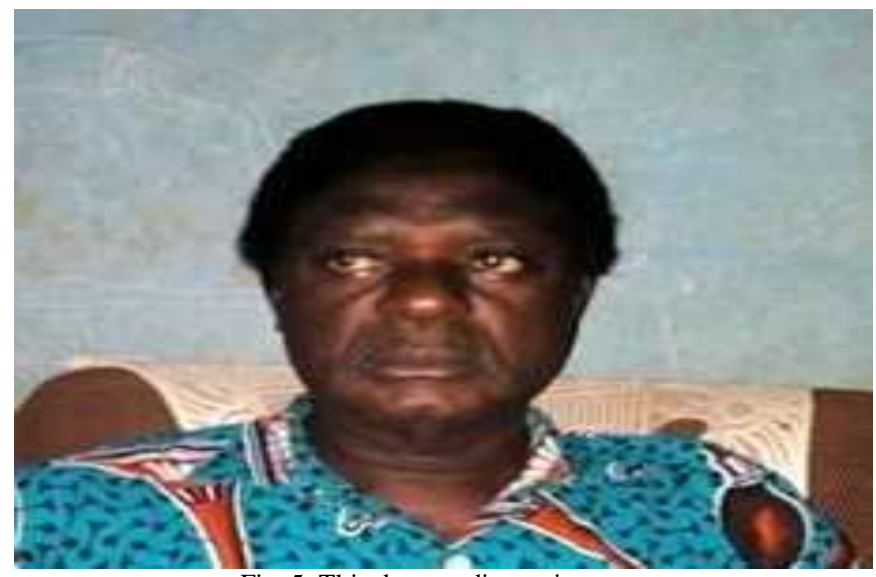

Fig. 5: This denotes disappointment.

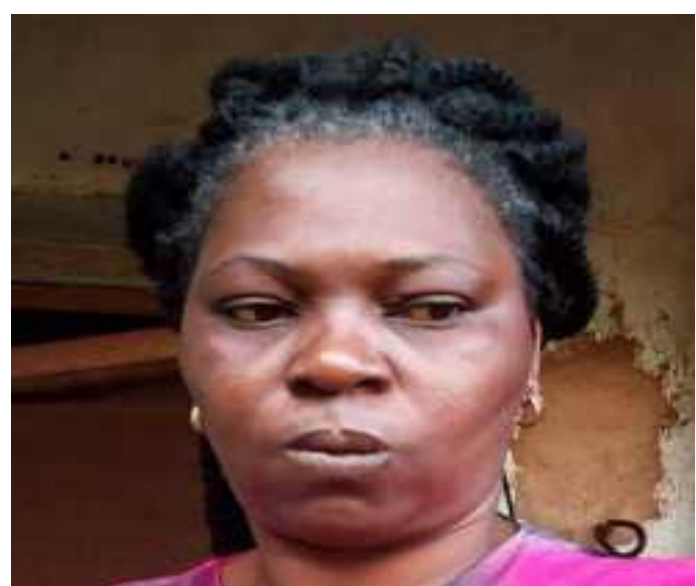

Fig. 6: This indicates "leave the presence of the visitor or shut your mouth up".

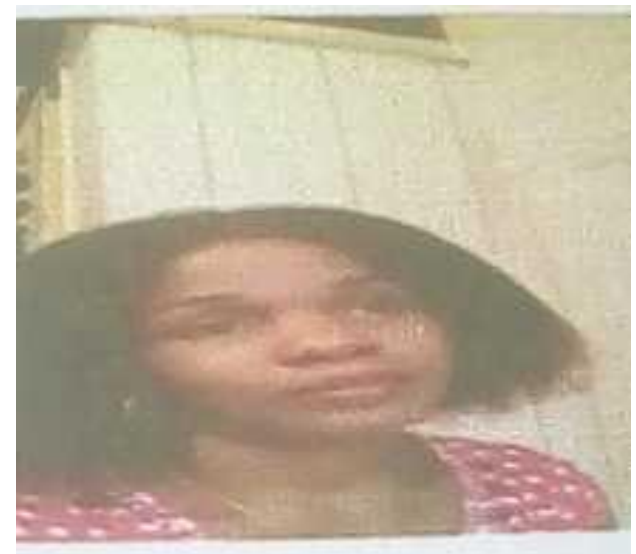

Fig. 7: This denotes interest. 


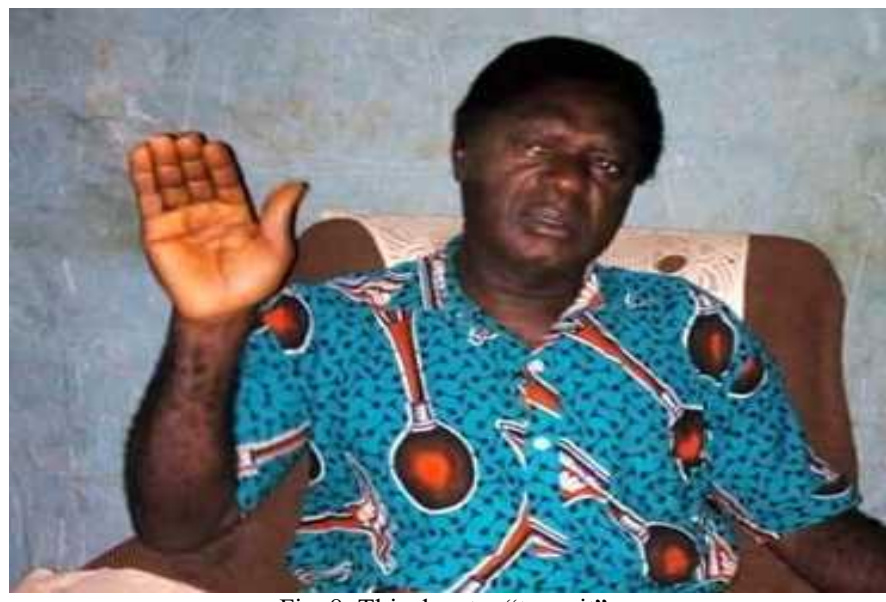

Fig. 8: This denotes "to wait".

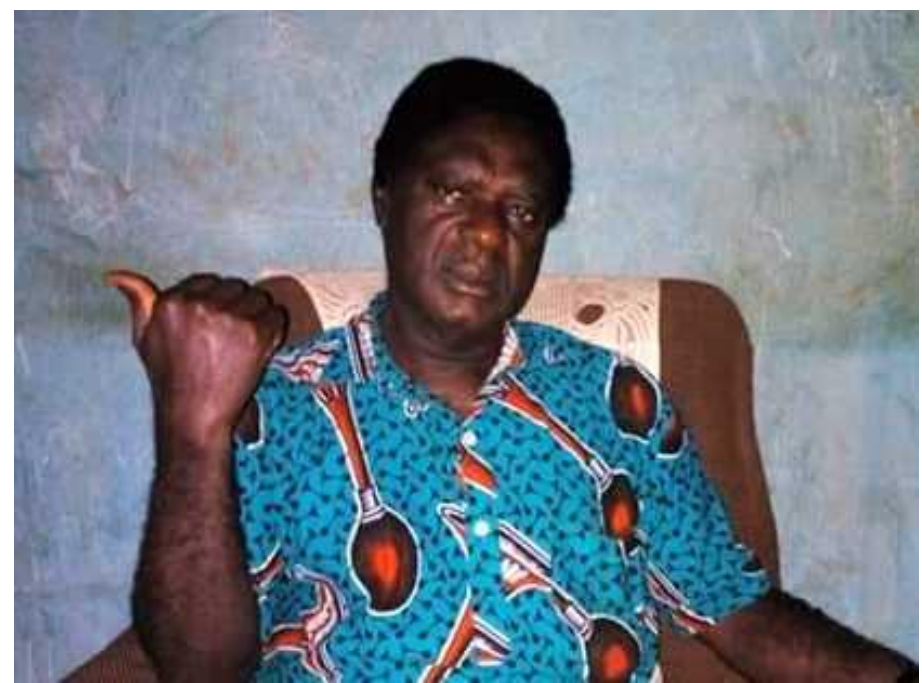

Fig. 9: This denotes get inside

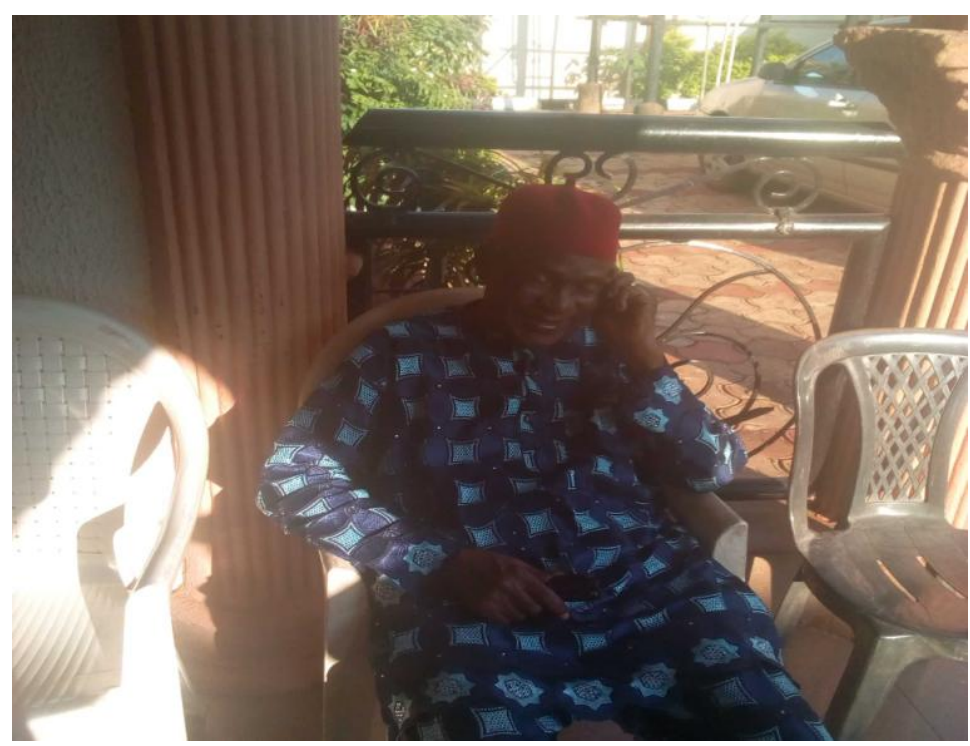

Fig. 10: This denotes slyness

\section{B. Semiotic Interpretations of the Body Expressions of Parents to Their Children}

Fig. 1 is a parent smiling, and the expression shows that he is in a bright mood despite the fact that he is old. This was captured when a visitor was making an impressive statement about his child and from the smile, the child saw in him a happy moment and detected the feeling of contentment and pride about their action. 
Figure 2 is a mother bidding her little child come closer by folding her fingers as her hand is raised, which indicates "to come." During an interview, she said that once the sign is done by her with smiles on her face, her child will quickly rush to meet her. But if she frowns, the child will run away thinking the mother will beat him/her for doing something wrong. Some other respondents on seeing the picture added that the sign shows a kind of reinforcement or applaud given to a child as a result of wonderful behaviour in front of the visitor.

Fig. 3 is a representation of anger and injunction to go in; the mother telling the child to go into the house in an angry and threatening mood. Her hands are pointing directly to the door of the house with her frowning. During the interview section, the mother explained that the child did something nasty in the presence of a visitor, hence she asked the child to leave their presence using those expressions both with eyes and hands.

Fig. 4 shows a representation of surprise and shock. The expressions are exhibited when the father of the child was no more comfortable with the child's manner of approach to their visitors. This was done unconsciously when the respondent's child was asked a question about a particular assignment by the visitor, which the parents expected him to keep quiet or pretend to have done it, but rather he did otherwise. The father was shocked by the child's action and communicated it to the child by that facial expression.

In fig 5 , there is an indication of disappointment. The father widens his eyes in show of disappointment of what the child did though without reprimanding the child verbally. This face scares the child away which he never came back till the visitors left.

In fig. 6, a sad look with a squeezed mouth shows an instruction to leave or to shut up. This expression is usually displayed with the face. This can also be displayed when a mother does not want her child to collect a gift from a visitor. It can also be used to reprimand a child who wants to ask a visitor for something. With the facial expression, one can easily notice that the woman is not happy, which the child can decode immediately and leave without being told.

In fig. 7, a focused face of the mother shows interest in what the child has to say. The respondent was listening to the child's speech in the presence of their visitors and this shows how interested she was, which gave the child more courage to speak. In this case, the eyes will be opened and concentrated on a particular place. The tongue may twist unconsciously. One who is focused may look upward and never blinks the eye.

In fig. 8, the expression indicating 'to stop' is usually displayed with the raising of all fingers. Once this expression is done, the children will realise what their parent requires of them, and in a coded way, they will keep quiet and stop whatever they are saying or doing.

In fig. 9, the expression indicates 'to get inside the house'. It is a sign that suggests to the children that they should excuse the visitor(s) and the parents. However, they are not expected to leave the house rather to go inside the house and wait. This sign is always used when the parents and the visitors are having their discussion outside. Receiving visitors under a shade is common in the culture of the study area especially when the weather is hot.

Fig. 10 indicates slyness. The respondent was unexpectedly complemented by the child in visitor's presence. When the picture was taken the child was complementing him on how handsome and good looking he was despite his age. This is mostly used to indicate that one is shy. It involved the lowering of the head and eyes, spread lips and nose with a puffed check. This sign can also be displayed when a child in the presence of a visitor asks their parent whether to collect something from the visitor. The situation at hand deprives the parent of the opportunity to decline even though the parent does not want the child to collect that.

\section{CONCLUSION}

So many body expressions used by parents to their children in Ovoko speech community were identified in the course of the research, out of which ten were used for this study. It revealed that all expressions used by the population have a meaning attached to it. The study successfully conducted semiotics analysis on the signs embedded on the graphic images of parents as used in communicating to their children. Various levels of meanings have been identified and analysed. The study finds out that a sign can connote more than one idea; therefore, the interpretation of body expression depends on the user and the interpreter. From these results, it has been proven that non-verbal communication is culture based and some aspects of non-verbal expressions or communication are universal. It is very pertinent to note that every culture and social group has its own peculiar body language. This research discovers that there is a meaning attached to every expression and as a result, the population should be aware that these non-verbal expressions which are the meaning of communicating ideas, emotions and messages are either culture specific or universal. Non-verbal communication is extremely complex yet integral part of overall human communication skills.

The researchers therefore, recommend that a study of the children's interpretation and opinion of the parents' body expression is a worthwhile academic undertaking in other to ascertain if the right perlocutionary response to the sign is always achieved.

\section{REFERENCES}

[1] Bloch, B \& Trager, G. L. (1942). Outline of linguistic analysis. Baltimore: Linguistic Society of America.

[2] Burgoon, J. K., \& Saine, T. J. (1978). The unspoken dialogue. Boston: Houghton. Mifflin.

[3] Carter, P. (2000). A Semiotic analysis of newspaper front Page photographs. Accessed on 2/2/21 from www.studymode.com>essay. 
[4] Cherry, K. (2018). Types of non-verbal communication. Accessed on 3/8/20 from www.verywellmind.com.

[5] De Saussure, F. (1916). Course in general linguistics, W. B. Baskin (transl.). New York: McGraw-Hill.

[6] Dzanic, M, (2013). The semiotics of contemporary advertising messages: decoding visuals. JEZIKOSLOVLJE 14(2-3), 475 485.

[7] Eberhardinger, M. J. (2012). A semiotic analysis of iconicity in Japanese manner posters. Accessed on 8/2/21. From http://doi.org/10.33234/ssr.10.8.

[8] Eco, U. (1976). A theory of semiotics. Bloomington: Indiana University Press.

[9] Feerreira, J. Barr, p. \& Noble J. (2005). The Semiotics of user interface redesign. New Zealand: Victoria University of Wellington Press.

[10] Feng, W. D. \& O’Halloran, K. (2012). Representing emotive meaning in visual images: A social semiotic approach. Journal of Pragmatics 44(14), 2067 - 2084.

[11] Fridlund, A. J. (1994). Human facial expression: An evolutionary view. San Diego, CA: Academic Press.

[12] Halliday, M. A. K. (1978). Language as social semiotics: The social interpretation of language and meaning. London: Edward Arnold.

[13] Hodge, R. \& Kress, G. (1988). Social Semiotics. Cambridge: Polity Press.

[14] Jewitt, C. Henriksen, B. (2016). Social semiotic multimodality. In N. M. Klug \& H. Stockl (eds.), Handbook spache im multimodalen kontex (Handbook of language in multimodal contexts). (pp. 145 -164). Berlin: De Gruyter.

[15] Mikoluk, K. (2013). Types of communication: Definition on non-verbal communications. Accessed from https//:www.udemy.com/blog/types-of-communication/ on February 10, 2021.

[16] Okoro, E. A. \& Day, C. R. (2013). Negotiating with global managers and entrepreneurs in sub-Saharan Africa - Nigeria: An analysis of non-verbal behaviour in intercultural business communication. International Journal of Academic Research and Social Science 3(8), $239-250$.

[17] Remland, M. S. (2008). Non-verbal communication in everyday life (3 $3^{\text {rd }}$ ed) Allyn \& Bacom (eds). Accessed on 20/1/2021 from DOI:10.4135/9781483399447.

[18] Sebeok, T. A. (2001). An introduction to semiotic ( $2^{\text {nd }}$ ed.). Toronto: University of Toronto Press.

[19] Tsotra, D., Janson M. \& Cecez-Kecmanovic D. (2004). Marketing on the internet: a semiotic analysis. Proceeding of the tenth Americas conference of Information System. New York.

[20] Verderber, R. F. (1975). Communicate. California: Wads worth publishing company

Bestman E. Odeh hails from Delta state and was born on $7^{\text {th }}$ June. He is a scholar who is interested in academic excellence. He got his B. A (Linguistics) and M.A Linguistics) at the University of Nigeria, Nsukka. Bestman specializes in Morphology, syntax and sociolinguistics.

He is an ASSISTANT LECTURER in the University of Nigeria Nsukka. He has co-authored many articles among which is: Slang usage among students in urban areas: An insight of Warri Metropolis, in Igboscholars International Journal of Igbo Scholars Forum, Nigeria, 13(1), 37 - 56.

Mr. Odeh is a member of the Igboscholars' Forum, Nigeria and also a member of Linguistics Association of Nigeria (LAN) and presently a PhD student in the Department of Linguistics, Igbo and Other Nigerian LASNGUAGES, University of Nigeria, Nsukka.

Linda Abugu hails from Enugu state, Nigeria. She got her B. A (Linguistics) from the Department of Linguistics, Igbo and Other Nigerian Languages, University of Nigeria, Nsukka. She specializes in Sociolinguistics.

Jacinta Eze is from Ovoko, Nsukka, Enugu state, Nigeria and was born on $30^{\text {th }}$ July. She got her B. A. in Linguistics and Igbo and M. A. in Sociolinguistics both in University of Nigeria Nsukka. She specialises in sociolinguistics, critical discourse analysis and pragmatics.

She is an ASSISTANT LECTURER in the University of Nigeria Nsukka. She has co-authored many published articles such as Hyponyms of insect in Ovoko lect. Journal of Language Teaching and Research 11(6), 988 - 994. Documentation of endangered dialect of Igbo language: Issues of greeting in Enugwu-Ezike dialect. Journal of Language Teaching and Research 12(1), 120 - 126 and host of others.

Mrs. Eze is a member of the Igboscholars' Forum, Nigeria and also a member of Linguistics Association of Nigeria (LAN).

Juliana Mamah hails from Enugwu-Ezike in Nsukka, Enugu state, Nigeria and was born on $10^{\text {th }}$ August. She got her B. A. in Linguistics and Igbo and M. A. in Psycholinguistics both in University of Nigeria Nsukka. She specializes in Psycholinguistics.

She is an ASSISTANT LECTURER in the University of Nigeria Nsukka. She has co-authored many published articles such as Documentation of endangered dialect of Igbo language: Issues of greeting in Enugwu-Ezike dialect. Journal of Language Teaching and Research 12(1), 120 - 126, Hyponyms of insect in Ovoko lect. Journal of Language Teaching and Research 11(6), 988 - 994 and host of others.

Mrs. Mamah is a member of the Igboscholars' Forum, Nigeria and also a member of Linguistics Association of Nigeria (LAN).

Augustina N. Eze is a native of Opi Nsukka in Enugu state, Nigeria and was born on $20^{\text {th }}$ December. She obtained her B.A, M.A and Ph.D in Linguistics from the University of Nigeria, Nsukka. She also obtained her Post Graduate Diploma in Education from the same University. 
She is a LECTURER II in University of Nigeria Nsukka. Augustina specialises in sociolinguistics. She has co-authored so many published articles among which is 'an X-bar analysis of aspect in Yoruba' in Ideal journal of Igbo studies, 12(2), 164-183.

Dr. Eze is a member of Linguistic Association of Nigeria (LAN) and Igboscholars' Forum, Nigeria. 